\title{
Finding The Structure Of Speaking Task Between A Student And Native Speaker Is More Reliable Scoring Than Looking At The Results Of Writing Or Reading Tests In Pandemy
}

\author{
Imam Dui Agusalim \\ Politeknik Elektronika Negeri Surabaya, Jalan Raya ITS, Sukolilo Surabaya 60111, Indonesia \\ E-mail address: idagusalim@gmail.com
}

DOI: 10.29322/IJSRP.10.11.2020.p10768

http://dx.doi.org/10.29322/IJSRP.10.11.2020.p10768

\begin{abstract}
Being able to speak to friends, colleagues, visitors and even strangers, in a foreign language or in a language which both speakers can understand, is surely the communication goal of very many learners. Yet speaking in a foreign language is very difficult, and competence in speaking takes a long time to develop. To speak in a foreign language, learners must master the sound system of the language, have almost instant access to appropriate vocabulary and be able to put words together intelligibly with minimal hesitation. In addition, they must also understand what is being said to them, and he able to respond appropriately to maintain good-natured relations or to achieve their communicative goals. Because speaking is done in real-time, learners' abilities to plan, process and produce the foreign language are burdened greatly. For that reason, the structure of speech is quite different from that of the written language, where users have time to plan, edit and correct what they produce. In other words the research is intended to find out the organisation of ideas that is implemented in natural conversation between students and native speakers. This portrait of communication is recommended as reliable scoring in pandemic situation.
\end{abstract}

Key words: Speaking Task, Scoring, Organisation of ideas

\section{Introduction}

In pandemic condition, it is not easy to do a reliable scoring for students who do the online multiple-choice test for written or reading tests. This happens because it is quite often for the teacher to find their work quite the same. The students always work together and share their work with their classmates by using headphone application such as Whatsapp; as result the teacher may give excellent score to the student who is not so qualified or mark the best student with bad score. When this happens, the scoring is not fair. There are two problems which clarify the teacher in scoring. They become the problems of this research.

1. Why is Speaking test more reliable than writing or reading tests in the pandemic moment?

2. How do the students organize their ideas in their conversation becomes the paramount of reliable scoring?

\section{Method}

\section{A. Research Method}

This research study design uses a Research and Development method. According to Sugiyono (2010: 407), method of research and development is the research method used to produce a particular product and test the effectiveness of the product. In this research, the method of testing, speaking with native speakers, is assumed to be reliable for giving valid scoring in an online test. There are two reasons why this speaking task test is very reliable. The speaking task is done individually, and it cannot be substituted by another person.

\section{B. Research Procedure}

To get the data of speaking performance, the students are assigned to have a task of making a free dialogue with native speakers which is in the form of audio recording (mp3 format). They may use their headphones, audio recorders or their laptop to do this individual task, so the students act as if they were journalists. And the steps of Research and Development method are as follows: 


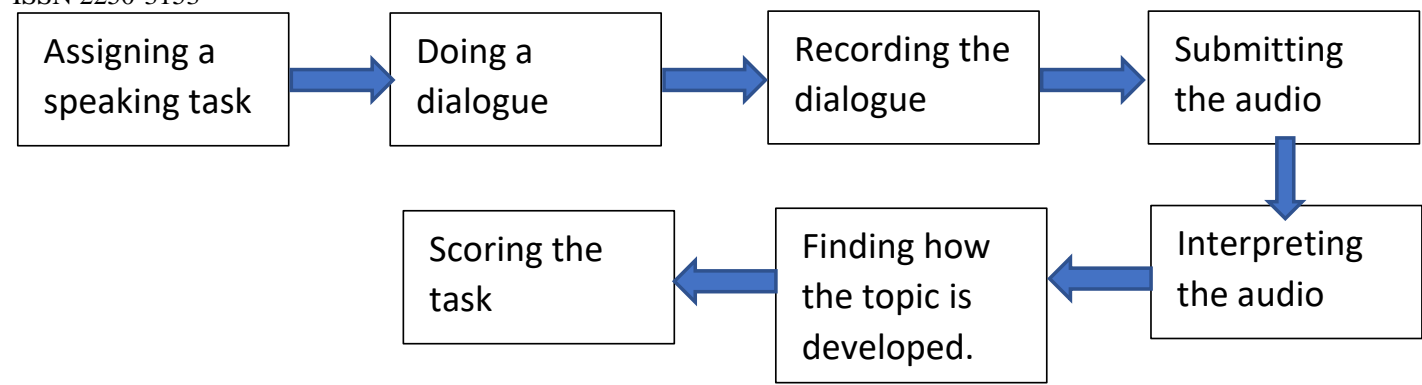

It is necessary to remind the students that their voice should be dominant when the recording is on site where the background voice might be louder. The dialogue can be done via the internet application such as skype or they can do the dialogue via whatsapp. When they have recorded their task, the result is submitted for their assessment.

\section{Analysing the Speaking Task}

The speaking task is referred to the test that includes plans that will be given to the students and done by the teacher as the assessor. The students are asked to practice using the English language for real communication in natural setting. The setting may take a face to face dialogue or distance communication via the internet. Nunan (1993: 59) defines a communicative task as:

... a piece of classroom work which involves learners in comprehending, manipulating, producing or interacting in the target language while their attention is principally focused on meaning rather than form. . . Minimally, a task will consist of some input data and one or more related activities and procedures. Input refers to the data that learners are to work on: it may be linguistic (e.g. a radio broadcast), non-linguistic (e.g. a set of photographs), or 'hybrid' (e.g. a road map). In addition, tasks will have, either explicitly or implicitly (and in most cases these are implicit), goals, roles of teachers and learners and a setting.

This definition is helpful for test development as well, because it details the elements that the task designer has to design: input, goals, roles and settings. Bachman and Palmer (1996: 44) have defined language use tasks in very similar terms. To modify their definition slightly for the specific context of speaking, speaking tasks can be seen as activities that involve speakers in using language for the purpose of achieving a particular goal or objective in a particular speaking situation. The emphasis in this definition is on goal-oriented language use, and it is appropriate for test tasks as well as events or 'tasks' outside testing situations. So the task is reliably used to test of the students' speaking performance.

Due to the pandemic condition, they are allowed to do this task by using skype or whatapp applications for making the conversation about anything they like. Besides, they can to talk in a mall, park, street, station, airport or in hotel. The results of recording are submitted as the data of reliable test for delivering their score.

The nature of the interaction, the sorts of tasks that are presented to the student, the questions asked, the topics presented, and the opportunities that are provided to show his or her ability to speak in a foreign language will show the student's performance in speaking skill. In addition to all the factors that may affect performance, the criteria used to assess the performance can vary enormously, from global assessments to detailed analytic scales. However, in this study the focus is on the way how the student create the performance of speaking task and how they organize their ideas in conversation. The scale in which his performance is interpreted by the assessor is bound to have an impact on the score that is ultimately awarded. To limit the complexity of assessment three levels: excellent, good and bad are used for scoring. When their speaking is organized well, such as from general to specific or sample, or a single topic explored until the details, their score is excellent. Their score is good when their conversation is done by moving from one topic to another. They don't have capability how to expand the conversation by talking about detail or providing examples. When they cannot talk much or their speech cannot be understood due to their poor pronunciation or they do not understood what is being spoken by the native speakers, their score is bad.

\section{Conclusion and Recommendation}

From the discussion and analysing of the speaking task done by several students, some conclusions can be described as the following:

1) In pandemic situation, written and reading test results can be shared easily among the students in classroom. Meanwhile, speaking test is more reliable than written test because the test cannot be done together with their classmates. No one complaints the scoring level that is made on the basis of speaking test. The speaking test referred to competence in pronunciation, structure, vocabulary, and understanding in communication.

2) In order to extend the dialogues, most students just move from one topic to another new topic. They do not explore the topic of the dialogues from general to specific; therefore, their competence level in general is classified as intermediate low level.

Meanwhile the recommendation can be expressed in the following: 
1) Written or reading tests are good for creating various activities in pandemic situation. For valid scoring, speaking test is more reliable.

2) Teachers of English should teach their students about the way how to organize ideas that are arranged from general to specific which may be used to extend the dialogue.

\section{References}

Bachman, L. F. and Palmer, A. 1996. Language Testing in Practice. Oxford: OUP

Nunan, D. 1993. Task-based syllabus design: selecting, grading and sequencing tasks. In G. Crookes and S. Gass (eds), Tasks in a Pedagogical Context: Integrating theory and practice. Clevedon: Multilingual Matters, pp. 55-68.

Sugiyono. 2010. Research Method in Quantitative, Qualitative Approach and R\&D. Bandung:

Alfabeta 